\title{
BONDING ABILITY OF DIFFERENT LINERS TO BULK-FILL RESIN COMPOSITE USING SILANE-CONTAINING ADHESIVE
}

\author{
Muhammad Samman *, Ola Barakat ${ }^{* *}$ and Hala Fares ${ }^{* * *}$
}

\begin{abstract}
Aims: To compare and evaluate the bonding ability of bulk-fill resin composite (RC) to four different liners: Biodentine (BD), TheraCal (TLC) - a novel resin-modified calcium silicate cement, resin-modified glass ionomer cement (RMGIC) and conventional glass ionomer cement (GIC) using a universal silane-containing adhesive and characterizing their failure modes.

Materials and Methods: Forty extracted intact human premolars with occlusal cavity (4-mm diameter and 2-mm height) were mounted in acrylic blocks and divided into four groups of ( $\mathrm{n}=10$ samples) each based on the liner used as group I; (BD), group II; (TLC), group III; (RMGIC) and Group IV; (GIC). Bulk-fill composite buildup of $3 \mathrm{~mm}$ diameter and $5 \mathrm{~mm}$ height was then bonded to each sample using universal adhesive. Shear bond strength (SBS) analysis was performed using materials testing machine at a cross-head speed of $0.5 \mathrm{~mm} / \mathrm{min}$.
\end{abstract}

Statistical Analysis: Statistical analysis was performed with one-way analysis of variance (ANOVA) and Tukey's post hoc test for numerical data while chi square test for categorical one.

Results: One-way analysis with ANOVA revealed significant difference in bond strength values between the different groups $(\mathrm{p}<0.001)$. The observed modes of failure were predominantly cohesive in Biodentine, TheraCal and GIC groups while RMGIC showed majority of mixed and minority adhesive failures.

Conclusions: Biodentine demonstrated lower bond strength values when immediately bonded to bulk-fill resin composite compared with RMGIC, TheraCal and GIC groups

\section{INTRODUCTION}

For decades, the restorative management of dental caries involved the placement of a lining on the floor and, when present, axial walls of the cavity. ${ }^{(1)}$ The placement of a lining was proposed for several reasons: to reduce the number of viable bacteria remaining close to the pulp, to induce development of reactionary/reparative dentine, to possibly remineralize remaining demineralized

\footnotetext{
*Assistant Professor, Dental Biomaterials Faculty of Dental Medicine, Al-Azhar University Cairo, Egypt.

** Associate Professor, Operative Dentistry, Faculty of Oral and Dental Surgery, Misr University for Science and Technology, Cairo, Egypt.

*** Associate Professor, Operative Dentistry, Faculty of Oral and Dental Surgery, Misr University for Science and Technology, Cairo, Egypt.
} 
hard tissues, to isolate the pulp against thermal and electric conduction, to protect pulpal cells against chemical irritants such as methacrylates from adhesives and to prevent the effects of restoration leakage on the pulp. ${ }^{(2)}$

The traditional lining materials include calcium hydroxide, glass ionomer, resin modified glass ionomer, and pure resinous liners with particles releasing therapeutic agents. The success of liners underneath resin composite (RC) depends not just on the bond quality of the liner to the dentin, yet additionally on the nature of bond amongst liner and overlying RC. Various researches suggested the use of resin-modified glass ionomer cement (RMGIC) instead of GI in the sandwich technique because of improved bond strength to $\mathrm{RC}$ due to its chemical bonding. (3),(4) The bond quality of RMGIC to RC varies relying upon the kind of adhesive utilized and it has been demonstrated that self-etch is superior to total etch. ${ }^{(5)}$

Extensive researches have been taking place in creating bioactive materials with a potential for remineralization. ${ }^{(6)}$ Bioactivity refers to apatiteforming capability while biomineralization is the ability to get tied down to the dentin through formation of a mineral-rich interfacial layer and taglike structure outspreading from the interfacial layer to the dentinal tubules. ${ }^{(7)}$

The evolution of bioreactive calcium silicate cement (Biodentine ${ }^{\mathrm{TM}}$ (BD) and TheraCal, etc.) set a landmark in the development of a unique category of materials combining bioactivity, biocompatibility, and strength. ${ }^{(8)}$

Biodentine $^{\mathrm{TM}}$ is recently being used as a dentine replacement material under composite restorations. A study by Hashem et al. showed no significant difference in bond strength between $\mathrm{BD}$ and $\mathrm{RC}$ in either self-etch or total etch mode. ${ }^{(9)}$

Theracal is a new light-cured resin-modified calcium silicate-filled base/liner material designed for direct and indirect pulp capping. Theracal exhibited physiochemical bonding to the dentin and is welltolerated by immortalized odontoblast cells. ${ }^{(10)}$

The utilization of bioactive liners underneath resin composite (RC) would clinically be more valuable than utilizing GI liners as they are biologically well-tolerated by the pulp tissue ${ }^{(11)}$ and have relatively higher re-mineralizing capability. ${ }^{(12)}$

Conventional resin based composite (RBCs) would be light cured in $2 \mathrm{~mm}$ thick increments of material. But, there is a demand to bulk cure RBCs in 4 to $6 \mathrm{~mm}$ increments to reduce clinical procedure times. The increasing popularity of restorative materials - so-called "bulk-fill" materials - are claimed to enable restoration build-up in layers up to $6 \mathrm{~mm}$ thick. This new material class includes flowable and packable types. ${ }^{(13)}$

Adhesive dentistry is a rapidly changing and evolving field. The basic principle of adhesion of composite resins to dental substrate is based on exchange processes in which inorganic dental material is replaced by synthetic resin. ${ }^{(14)}$ Currently there is a tendency to simplify bonding procedures which introduced the self-etching adhesive concept. Recently, a new single bottle universal or multimode adhesive with silanes was introduced that simplifies the bonding procedure as single adhesive and can be used in self-etch or total etch or selective etch mode and on any surfaces (enamel, dentin, any direct, or indirect restorative materials) without additional primer. ${ }^{(4)}$

The bond strength of liner to restorative materials has been an issue of concern. To our knowledge little/no study till now has compared the bonding ability between TLC, BD, and RMGIC to bulk-fill $\mathrm{RC}$ using universal adhesive. Hence, in the present study the shear bond strength (SBS) of BD/TLC/ RMGI/ GIC to bulk-fill composite using universal adhesive was evaluated and compared and the null hypothesis was that there is no difference in the SBS within each substrate (TLC/BD/RMGI/GIC). The study also intended to categorize the specific modes of failure. 


\section{MATERIALS AND METHODS}

The materials used, composition, manufacturer and mode of application are shown in (Table 1).

TABLE (1) Materials composition, manufacturer and mode of application

\begin{tabular}{|c|c|c|c|}
\hline Material & Material composition & Manufacturer-lot \# & Mode of application \\
\hline $\begin{array}{l}\text { Tricalcium } \\
\text { silicate cement - } \\
\text { Biodentine }\end{array}$ & $\begin{array}{l}\text { Powder: di-, tri-Ca silicate, } \mathrm{CaCO} 3 \text {, } \\
\text { Fe, and } \mathrm{Zr} \text { oxides } \\
\text { Liquid: } \mathrm{H} 2 \mathrm{O}, \mathrm{CaCl} 2 \text {, and modified } \\
\text { polycarboxylate }\end{array}$ & $\begin{array}{c}\text { Septodont, } \\
\text { St Maur-des-Fosses, } \\
\text { France-B06211 }\end{array}$ & $\begin{array}{l}\text { Five drops of liquid added to the } \\
\text { capsule. Capsule triturated at } 4,000 \mathrm{rpm} \\
\text { for } 30 \mathrm{~s}\end{array}$ \\
\hline $\begin{array}{l}\text { light-cured resin- } \\
\text { modified calcium } \\
\text { silicate cement - } \\
\text { TheraCal }\end{array}$ & $\begin{array}{l}\text { 45\% wt type III Portland cement, } \\
10 \% \text { wt radiopaque component, } 5 \% \\
\text { wt hydrophilic thickening agent } \\
\text { (fumed silica) and approximately } \\
45 \% \text { resin }\end{array}$ & $\begin{array}{c}\text { Bisco Inc, } \\
\text { Schamburg, IL, USA } \\
1700000367\end{array}$ & $\begin{array}{l}\text { Inject the material into cavity in } 1 \mathrm{~mm} \\
\text { layer - light cure } 20 \mathrm{~s}\end{array}$ \\
\hline $\begin{array}{l}\text { Resin-modified } \\
\text { glass ionomer } \\
\text { cement (RMGIC) }\end{array}$ & $\begin{array}{c}\text { Powder:Fluoroaluminosilicate glass } \\
\text { Liquid: H2O, polyacrylic acid, } \\
\text { HEMA, }\end{array}$ & $\begin{array}{c}\text { Harvard Dental } \\
\text { International GmbH } \\
\text { Hoppegarten, } \\
\text { Germany } 7510294\end{array}$ & $\begin{array}{l}\text { Mixing premeasured capsule in } \\
\text { amalgamator for } 10 \mathrm{~s} \text {. light cure } 20 \mathrm{~s}\end{array}$ \\
\hline $\begin{array}{l}\text { Glass ionomer } \\
\text { cement - GIC }\end{array}$ & $\begin{array}{c}\text { Powder: aluminosilicate glass } \\
\text { Liquid: } \mathrm{H} 2 \mathrm{O} \text {, polyacrylic acid, and } \\
\text { tartaric acid }\end{array}$ & $\begin{array}{c}\text { Medi-CEM; } \\
\text { PROMEDICA } \\
\text { Dental GmbH } \\
\text { Hoppegarten, } \\
\text { Germany - } 1722569\end{array}$ & $\begin{array}{l}\text { Mixing powder/liquid ratio } 1: 1 \\
\text { Fill the cavity }\end{array}$ \\
\hline $\begin{array}{c}\text { Bulk-fill resin } \\
\text { composite }\end{array}$ & $\begin{array}{l}\text { Matrix; urethane dimethacrylate } \\
\text { (UDMA) Triethyleneglycol } \\
\text { Dimethacrylate (TEGDMA) Di- and } \\
\text { trimethacrylate resins Carboxylate } \\
\text { Filler; } 85.5 \% \mathrm{w} \text { and } \% 66.4 \mathrm{~V} \text { - } \\
\text { silanated strontium aluminum sodium } \\
\text { fluoride phosphate silicate glass }\end{array}$ & $\begin{array}{c}\text { Quixfill } \\
\text { Dentsply DETREY } \\
\text { GmbH. } \\
\text { Konstantz. Germany } \\
- \\
1509000951\end{array}$ & $\begin{array}{l}\text { Insert in single increment - light cure } \\
\text { for } 40 \mathrm{~s}\end{array}$ \\
\hline $\begin{array}{c}\text { Universal dental } \\
\text { adhesive }\end{array}$ & $\begin{array}{c}\text { MDP phosphate monomer, } \\
\text { dimethacrylate resin, polyalkenoic } \\
\text { acid copolymer, filler , ethanol, water, } \\
\text { initiator - Silane }\end{array}$ & $\begin{array}{c}\text { Single Bond } \\
\text { Universal }^{\mathrm{TM}}, 3 \mathrm{M} \\
\text { ESPE, St. Paul, MN, } \\
\text { USA } 502225\end{array}$ & $\begin{array}{l}\text { applied on liner surface with a bristle } \\
\text { brush, rubbed for } 20 \mathrm{~s} \text { followed } \\
\text { by gentle air drying with oil-free } \\
\text { compressed air for approximately } 5 \mathrm{~s} \\
\text { to evaporate the solvent and was light } \\
\text { cured for } 10 \mathrm{~s}\end{array}$ \\
\hline
\end{tabular}

Tooth Preparation; Forty human intact premolars extracted for orthodontic reasons were collected for the study and the teeth were cleaned with ultrasonic scalers and stored in saline. These teeth roots were invested in acrylic resin blocks using a cylinderical mould that was $15 \mathrm{~mm} / 25 \mathrm{~mm}$ in dimension. The occlusal surfaces were grinded perpendicular to the long axis of the tooth with a high-speed diamond disc (KG Sorensen, São Paulo, SP, Brazil) to obtain a flat surface such that the occlusal surfaces were flush with the acrylic surface. Then a cavity of $4 \mathrm{~mm}$ diameter and $2 \mathrm{~mm}$ depth was prepared (Figure 1; $a$ and $b$ ) to retain the liner using a highspeed handpiece with a cylindrical 
carbide bur (56;KG Sorensen, São Paulo, SP, Brazil). The cavity dimensions were verified by a digital caliper (accuracy $\pm 0.01 \mathrm{~mm}$ ). Carbide bur was changed every 3 preparations. These 40 samples were randomly divided into four groups $(n=10 /$ group): Group I - BD; (Biodentine ${ }^{\mathrm{TM}}$, Septodont, Saint-Maur-des-Fossts, Creteil, France), Group II - TLC; (Theracal LC TM , Bisco Inc, Schamburg, IL, USA), Group III - RMGIC; (Harvard Dental International $\mathrm{GmbH}$ Hoppegarten, Germany) and Group IV- GIC; (Medi-Cem , PROMEDICA Dental, Hoppegarten, Germany) and the cavities were filled as per manufacturer's instructions [Table 1] and their surfaces were not finished to mimic the clinical scenario. Universal adhesive, (Single Bond Universal TM , 3M ESPE, St. Paul, MN, USA) was applied on TLC/BD/RM GIC -GIC surface with a bristle brush, rubbed for $20 \mathrm{~s}$ followed by gentle air drying with oil-free compressed air for approximately $5 \mathrm{~s}$ to evaporate the solvent and then light cured for $10 \mathrm{~s}$ after placing the polyethylene tube (4-mm diameter, 5-mm height) as per the manufacturer's instructions. Bulk-fill RC (Quixfill, Dentsply DETREY GmbH. Konstantz. Germany) was placed in the tube (Figure 1; c) and lightcured with a light-emitting diode light-curing unit (LED 105 Monitex Industrial Co.,Ltd,China) with an intensity of $1,200 \mathrm{mV} / \mathrm{cm} 2$ for $20 \mathrm{~s}$. After the completion of RC curing, the polyethylene tubes were removed with a sharp knife. All specimens were incubated at $37^{\circ} \mathrm{C}$ in water for $24 \mathrm{~h}$.

\section{Measurement of shear bond strength}

A circular interface modified lap shear test was designed to evaluate the bond strength. All samples were individually and horizontally mounted on a computer controlled material testing machine (Model 3345; Instron Industrial Products, Norwood, USA) with a loadcell of $5 \mathrm{kN}$ and data were recorded using computer software (Bluehill Lite; Instron Instruments). Samples were secured to the lower fixed compartment of testing machine by tightening screws through metallic custom-made housing device with central cavity into which the acrylic block fit (dimensions;25x25 mm). Shearing test was done by compressive mode of load applied at resin-liner interface using a metallic rod with halfcircle shaped end attached to the upper movable compartment of testing machine traveling at crosshead speed of $0.5 \mathrm{~mm} / \mathrm{min}$ (Figure d). The load required to de-bonding was recorded in Newtons.

Shear bond strength calculation; The load at failure was divided by bonding area to express the bond strength in $\mathrm{MPa} ; \tau=\mathrm{P} / \pi \mathrm{r} 2$ where $; \tau=$ shear bond strength ( $\mathrm{MPa}, \mathrm{P}=\operatorname{load}$ at failure $(\mathrm{N}), \pi=3.14$ and $\mathrm{r}=$ radius of composite $\operatorname{disc}(\mathrm{mm})$

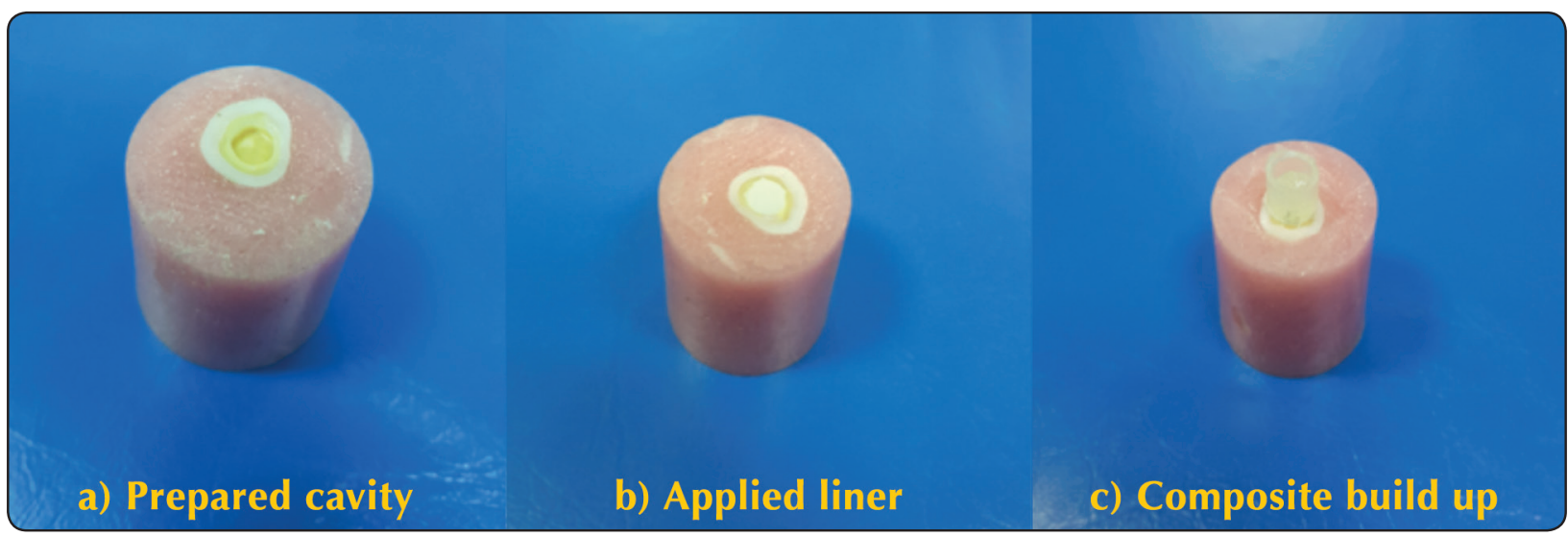

Fig. (1) Steps of shear bond strength sample preparation 


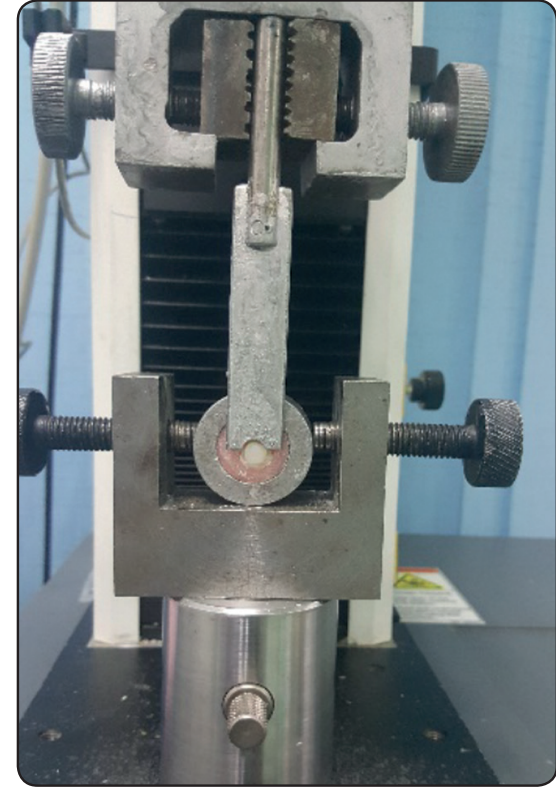

Fig. (2) Shear bond strength sample mounted onto testing machine

Failure analysis; The fractured test specimens were examined under a stereomicroscope (Leica MZ6, Mannheim, Germany) at a magnification of $x$ 25 and fractures were classified as follows: Cohesive failure - Failure within TLC/BD/RMGIC/GIC or $\mathrm{RC}$, adhesive failure - Failure at RC- TLC/BD/ RMGIC-GIC interface, and mixed failure - When two modes of failure occur simultaneously. Fracture analysis was performed by a single observer who was completely uninformed about the experimental groups.

Statistical analysis; statistical analysis was performed by using MS Excel 2010 and Asistat 7.6 statistics software for Windows (Campina Grande, Paraiba state, Brazil). Descriptive statistical data was presented in the form of mean and standard deviation. Since a normal distribution was observed for all the bond strength values of all groups, oneway analysis of variance (ANOVA) was performed to assess the significance between the different groups followed by Tukey's post hoc tests were used for multiple group comparisons. $P$ values $\leq 0.05$ considered to be statistically significant in all tests.

\section{RESULTS}

The mean shear bond strength and standard deviation are shown in Table (2) and graphically drawn in figure (3:a). The highest shear bond strength mean \pm SD values were recorded with RMGIC group $(6.962 \pm 0.33 \mathrm{MPa})$ followed by TheraCal group $(3.722 \pm 0.74 \mathrm{MPa})$ then GIC group (3.491 $\pm 0.96 \mathrm{MPa}$ ) while the lowest shear bond strength mean \pm SD values were recorded for biodentine group $(2.257 \pm 0.68 \mathrm{MPa})$. One-way analysis with ANOVA revealed significant difference in bond strength values between the different groups $(\mathrm{p}<0.001)$. Tukey's post-hoc test showed nonsignificant difference between (TheraCal and GIC) groups.

The observed modes of failure were predominantly cohesive in Biodentine group. In TheraCal and GIC the modes of failures were somehow similar with predominant cohesive failure and little adhesive or mixed failure while RMGIC showed majority of mixed and minority adhesive failures with no record for cohesive failure. Chi square test showed significant difference in failure mode distribution between the different groups $(p<0.5)$. table (2) and figures (3:b and 4$)$ 
TABLE (2) Comparison of shear bond strength results (Mean \pm SD) and failure analysis (\%) between all liner groups

\begin{tabular}{|c|c|c|c|c|c|}
\hline \multicolumn{2}{|c|}{ Variable } & Shear bond strength & \multicolumn{3}{c|}{ Failure mode } \\
\cline { 3 - 6 } & Biodentine & $2.257^{\mathrm{C}} \pm 0.68$ & Cohesive & Adhesive & Mixed \\
\hline \multirow{3}{*}{ Liner group } & TheraCal & $3.722^{\mathrm{B}} \pm 0.74$ & $5(50 \%)$ & $2(20 \%)$ & $3(10 \%)$ \\
\cline { 2 - 6 } & RMGIC & $6.962^{\mathrm{A}} \pm 0.33$ & $0(0 \%)$ & $3(30 \%)$ & $7(70 \%)$ \\
\cline { 2 - 6 } & GIC & $3.491^{\mathrm{B}} \pm 0.96$ & $5(50 \%)$ & $3(30 \%)$ & $2(20 \%)$ \\
\hline \multirow{2}{*}{ Statistics } & P value & $<0.0001^{*}$ & & $0.0207^{*}$ \\
\hline
\end{tabular}

Different letter indicating significant $(p<0.05)$

$$
\text { *; significant }(p<0.05)
$$

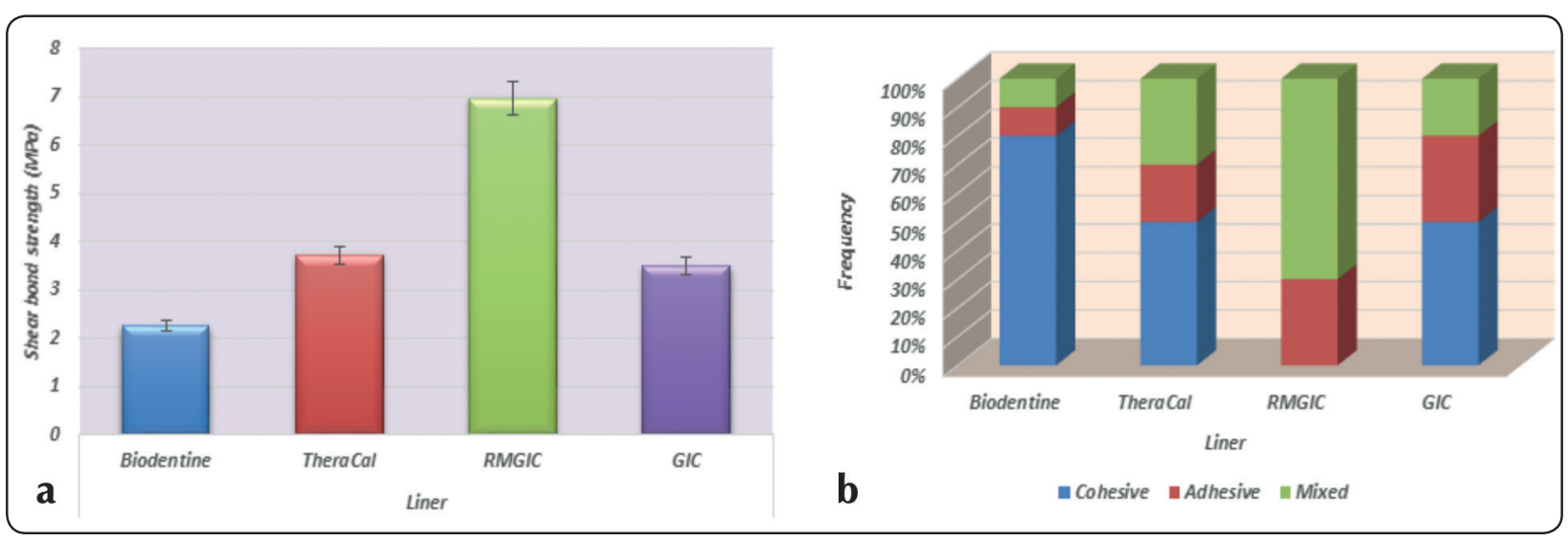

Fig. (3) Shear bond strength means values (3:a) and failure mode distribution (3:b) for liner groups

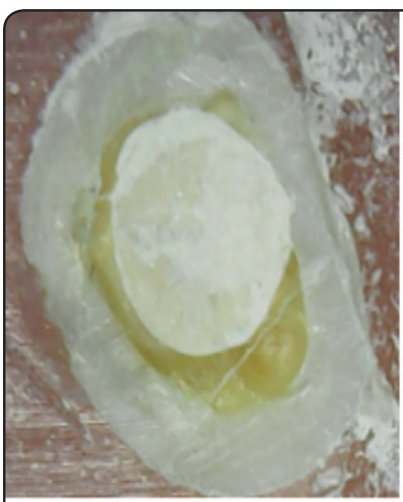

a) Cohesive in Biodentine

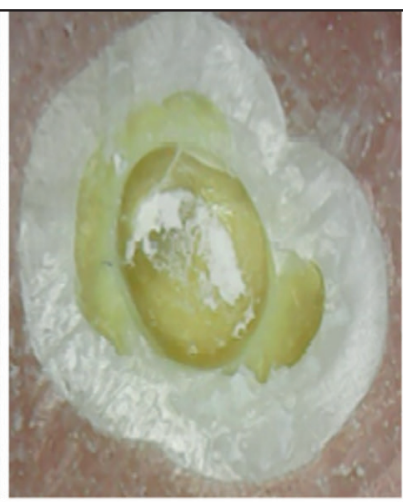

b) Mixed in TheraCal

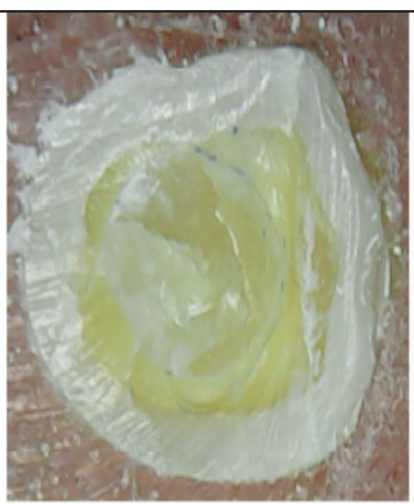

c) Mixed in RMGIC

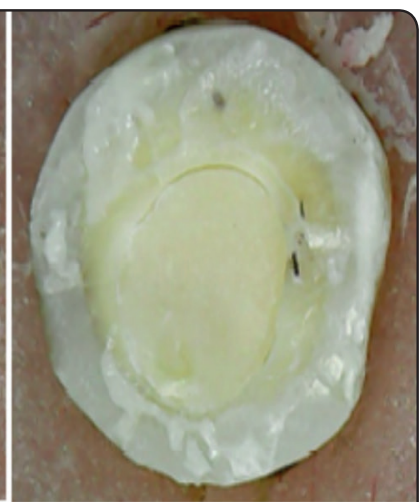

d) Adhesive in GI

Fig. (4) Representative stereomicroscopic images for different failure modes within all groups $(\times 25)$ 


\section{DISCUSSION}

Most of the bond strength studies are achieved using dentin pulp floor or axial walls as substrate. Studies on flat dentin surfaces are far from reality, since they do not take into account the clinical situation including presence of liner, resin insertion technique or stress induced in cavity geometry. In the present study, shear bond strength of Biodentin, Theracal, RMGIC and Glass ionomer cement liners to bulk-fill composite was evaluated and compared.

Biodentine $^{\mathrm{TM}}$ and TheraCal LC ${ }^{\mathrm{TM}}$ are calcium silicate-based bioactive liners that are proposed as alternatives to glass ionomers (GIs). Both materials release calcium and silicon ions into the underlying dentin. ${ }^{(15)}$ According to Saito et al. silica is a stronger inducer for dentin matrix remineralization than fluoride ions of RMGIC. Cytotoxicity studies showed that Biodentine/TheraCal is well-tolerated by immortalized odontoblast cells. These are the cells that retained their ability to divide with stable phenotypic protein expression profiles and ability to produce mineralized dentin extracellular matrix under in vitro conditions. ${ }^{(12)}$

Biodentine is a biocompatible bioactive material which may simulate dentine regeneration by inducing odontoblast differentiation from pulp progenitor cells and has been suggested to be used as a liner under resin composite restorations. ${ }^{(16)}$ It has higher compressive strength values than reinforced zinc oxide-eugenol cement, comparative performance to a resin modified GIC regarding microleakage when used as a dentine substitute $^{(17)}$ and better marginal adaptation to dentine compared to MTA cement and GIC. ${ }^{(18)}$

In the present study, methacryloyloxydecyl dihydrogen phosphate (MDP)-based, universal adhesive with silanes was selected. This self-etch 10-MDP-based adhesive shows chemical bonding to $\mathrm{Ca}$ ions, and $\mathrm{Al}$ and zirconium oxides. ${ }^{(19,20)}$ The bifunctional silane molecule bonds chemically to silica-containing materials and has methacrylate functionality that allows chemical union with resinous substrate. Silanes also act as adhesion promoters by enhancing the wetting ability of the adhesive system. This adhesive was selected in this study, aiming for additional chemical bonding with Ca releasing bio active liners. ${ }^{(21)}$

There are numerous methods for assessing the adhesion of a dental material to dentin, including tensile, shear, and push-out bond strength tests. In this study modified shear-lap was done based on its relative easiness, simplicity, inexpensive and reproducibility compared to tensile bond testing and to avoid friction effect that occurs in push out bond testing. (22)

Materials intended for posterior bulk-filling placement can be applied in one increment up to 4 $\mathrm{mm}$ thickness, thus skipping the time-consuming layering process. Improved self-leveling ability, decreased polymerization shrinkage stress, reduced cuspal deflection in standardized class II cavities and good bond strengths regardless of the filling technique and the cavity configuration are reported. ${ }^{(13)}$

In this study, RMGIC group and TheraCal group showed significantly higher bond strengths than Biodentine group. This may be related to their resin contents that attain early cohesive strength on photo activation. Also, this might be due to similar resin chemistry promoting chemical adhesion with $\mathrm{RC}$ as proposed for RMGIC. Hydroxyethyl methacrylate (HEMA) incorporated into the TheraCal and RMGIC forms a chemical bond with the resin of the composite. Additional chemical union is due to copolymerization of unreacted methacrylate groups present in the oxygen-inhibited layer of TheraCal / RMGIC with those of composite resin. (23), (24) The resin bonding agent intermixes with both composite and TheraCal /RMGIC by true chemical bonding to create a strong interface.

Biodentine group showed the least SBS means, which may have been due to low early strength of 
the material per se and this was in agreement with previous studies. ${ }^{(4,9)}$ Biodentine is a porous material that needs at least 2 weeks' time for crystallization of hydrated calcium silicate gel to attain bulk strength adequate to withstand the polymerization stresses. ${ }^{25}$ In the present study, bonding was performed to Biodentine immediately after $12 \mathrm{~min}$ to describe a single appointment clinical procedure. This might be the reason for low bond strength and cohesive failures in Biodentine.

Failure analysis (Figures 3:b and 4) revealed that higher bond strengths were often associated with 'mixed' or 'cohesive' failures in liner. Though the SBS of TheraCal and RMGIC groups were comparable, the failure modes were predominantly cohesive in TheraCal group while RMGIC group showed $70 \%$ mixed failures and $30 \%$ adhesive failures. Cohesive failure in TheraCal could have been due to its low bulk strength. TheraCal, a resin-modified (RM) calcium silicate cement is a combination of a HEMA/TEGDMA-based resin and calcium-silicate powder. On light activation, HEMA and TEGDMA monomers create a polymeric network able to stabilize the outer surface of the cement. Thus, formed poly-HEMA is hydrophilic and favors the absorption of moisture and triggers a second setting reaction that is hydration of calcium silicate particles with liberation of calcium ions. (7) TheraCal releases more $\mathrm{Ca}$ ions than RMGIC. Hence, a chemical bonding among adhesive and $\mathrm{Ca}, \mathrm{Al}, \mathrm{Zr}$, and silicon ions of TheraCal may have resulted in closer bond strength values as RMGIC group despite its low bulk strength.

\section{CONCLUSION}

Within the limitations of this in vitro study, the following conclusions might be drawn:

1. Biodentine demonstrated significantly lower bond strength values when immediately bonded to bulk-fill resin composite. The mode of failure was cohesive within Biodentine, indicating its weakness in its initial setting phase.
2. This necessitates paying attention towards the importance of leaving Biodentine for longer time to reach its final strength before the application of composite restoration.

3. RMGIC and TheraCal accomplished satisfactory bond strength to withstand condensation forces and stress from overlying composite resin due to the presence of a resin matrix.

4. Bulk-fill composite restoration can be placed immediately over TheraCal and RMGIC as alternatives to glass ionomers, completing the procedure in single visit

5. The interface integrity can be preserved by the composite insertion technique and by the type of liner used

\section{REFERENCES}

1. Weiner R. Liners and bases in general dentistry. Aust Dent J 2011: 56 (Suppl. 1);11-22.

2. Blum IR, Younis N, Wilson NH. Use of lining materials under posterior resin composite restorations in the UK. J Dent. 2017;57:66-72.

3. Farah CS, Orton VG, Collard SM. Shear bond strength of chemical and light-cured glass ionomer cements bonded to resin composites. Aust Dent J 1998; 43:81-6.

4. Deepa VL, Dhamaraju B, Bollu IP, Balaji TS. Shear bond strength evaluation of resin composite bonded to three different liners: TheraCal LC, Biodentine, and resin-modified glass ionomer cement using universal adhesive: An in vitro study. J Conserv Dent 2016; 19:166-70.

5. Arora V, Kundabala M, Parolia A, Thomas MS, Pai V Comparison of the shear bond strength of RMGIC to a resin composite using different adhesive systems: An in vitro study. J Conserv Dent 2010; 13:80-3.

6. Watson TF, Atmeh AR, Sajini S, Cook RJ, Festy F. Present and future of glass-ionomers and calcium-silicate cements as bioactive materials in dentistry: Biophotonics-based interfacial analyses in health and disease. Dent Mater 2014; 30:50-61.

7. Gandolfi MG, Taddei P, Siboni F, Modena E, Ciapetti G, Prati C. Development of the foremost light-curable calcium-silicate MTA cement as root-end in oral surgery. 
Chemical-physical properties, bioactivity and biological behaviour. Dent Mater 2011; 27:134-57.

8. Camilleri J, Laurent P, About I., "Hydration of biodentine, theracal LC, and a prototype tricalcium silicate-based dentin replacement material after pulp capping in entire tooth cultures," J Endod 2014;40: 1846-54.

9. Hashem DF, Foxton R, Manoharan A, Watson TF, Banerjee A. The physical characteristics of resin composite-calcium silicate interface as part of a layered/laminate adhesive restoration. Dent Mater 2014;30: 343-9.

10. Hebling J, Lessa FC, Nogueira I, Carvalho RM, Costa CA. Cytotoxicity of resin-based light-cured liners. Am J Dent 2009; 2:137-42.

11. Cannon M, Gerodias N, Viera A, Percinoto C, Jurado R. Primate pulpal healing after exposure and TheraCal application. J Clin Pediatr Dent 2014; 38:333-7.

12. Saito T, Toyooka H, Ito S, Crenshaw MA. In vitro study of remineralization of dentin: Effects of ions on mineral induction by decalcified dentin matrix. Caries Res 2003; 37:445-9.

13. Ilie N, Schöner C, Bücher K, Hickel R. An in-vitro assessment of the shear bond strength of bulk-fill resin composites to permanent and deciduous teeth. J Dent. 2014;42:850-5.

14. Van Meerbeek B, De Munck J, Yoshida Y, Inoue S, Vargas M, Vijay P, et al. Adhesion to enamel and dentin: current status and future challenges. Operative Dentistry-University of Washington. 2003;28:215-35.

15. Gandolfi MG, Siboni F, Botero T, Bossù M, Riccitiello F, Prati C. Calcium silicate and calcium hydroxide materials for pulp capping: Biointeractivity, porosity, solubility and bioactivity of current formulations. J Appl Biomater Funct Mater 2015; 13:43-60.
16. Koubi G, Colon P,. Franquin J. Clinical evaluation of the performance and safety of a new dentine substitute, Biodentine, in the restoration of posterior teeth - a prospective study. Clini Oral Invest 2013;17: 243-9.

17. Raskin A, Eschrich G, Dejou J, and About I. In vitro microleakage of Biodentine as a dentin substitute compared to Fuji II LC in cervical lining restorations. Journal of Adhesive Dentistry. 2012;14: 535-42.

18. Sulaiman JMA. An in vitro SEM comparative study of dentine-biodentine interface. International Dental Journal. 2013;63 (suppL 1):1-98.

19. Yoshida Y, Nagakane K, Fukuda R, Nakayama Y, Okazaki M, Shintani H, et al. Comparative study on adhesive performance of functional monomers. J Dent Res 2004; 83:454-8.

20. Blatz MB, Sadan A, Kern M. Resin - ceramic bonding: A review of the literature. J Prosthet Dent 2003; 89:268-74.

21. Söderholm KJ, Shang SW. Molecular orientation of silane at the surface of colloidal silica. J Dent Res 1993; 72:1050-4.

22. Wang M, Kornfield JA. Measuring shear strength of soft-tissue adhesives. J Biomed Mater Res Part B 2012:100:618-23.

23. Li J, Liu Y, Liu Y, Söremark R, Sundström F. Flexure strength of resin-modified glass ionomer cements and their bond strength to dental composites. Acta Odontol Scand $1996 ; 54: 55-8$

24. Kerby RE, Knobloch L. The relative shear bond strength of visible light-curing and chemically curing glass-ionomer cement to composite resin. Quintessence Int 1992; 23:641-4.

25. Bachoo IK, Seymour D, Brunton P. A biocompatible and bioactive replacement for dentine: Is this a reality? The properties and uses of a novel calcium-based cement. $\mathrm{Br}$ Dent J 2013;214: E5. 